\title{
Influence of obesity on localized prostate cancer patients treated with radical prostatectomy
}

\author{
Yuan-Yuan Qu ${ }^{1,2, *}$, Bo Dai ${ }^{1,2, *}$, Yun-Yi Kong ${ }^{2,3}$, Kun Chang ${ }^{1,2}$, Ding-Wei Ye ${ }^{1,2, *}$, Xu-Dong Yao ${ }^{1,2}$, \\ Shi-Lin Zhang ${ }^{1,2}$, Hai-Liang Zhang ${ }^{1,2}$ and Wei-Yi Yang ${ }^{1,2}$
}

This study aimed to investigate the association between different anthropometric measures of obesity and clinicopathological characteristics in Chinese patients with clinically localized prostate cancer (PCa). A total of 734 patients with clinically localized PCa who underwent radical prostatectomy (RP) were included in this study. Clinical and pathological data from each patient were collected. Anthropometric measures of abdominal adiposity were measured from T2-weighted sagittal localisation images from magnetic resonance imaging (MRI) for 413 (56.3\%) patients. Patient clinical and pathological characteristics were compared across body mass index (BMI) groups. Univariable and multivariable logistic regression models were used to address the influence of the preoperative total testosterone level and anthropometric measures of obesity on pathological outcomes. In the multivariate analysis, BMI was not significantly associated with any pathological outcomes. However, the percentage of visceral adipose tissue (VAT\%) was an independent predictor of a pathological Gleason score $\geqslant 8(P<0.001)$, extracapsular extension (ECE; $P=0.002$ ) and seminal vesicle invasion ( $S V I ; P=0.007$ ). More importantly, we found that the preoperative total testosterone level was significantly correlated with the VAT\% (Pearson's correlation coefficient: -0.485 , $\boldsymbol{P}<0.001$ ) and subcutaneous adipose tissue (SAT; Pearson's correlation coefficient: $0.413, P<0.001$ ). In conclusion, the results of this study suggest that abdominal fat distribution, and particularly VAT\%, is associated with a risk of advanced PCa. Moreover, our present study confirms a significant inverse correlation between visceral adiposity and testosterone. Further studies are warranted to elucidate the biological mechanisms underlying the relationship between abdominal adiposity and the aggressiveness of $\mathrm{PCa}$.

Asian Journal of Andrology (2013) 15, 747-752; doi:10.1038/aja.2013.104; published online 16 September 2013

Keywords: body mass index (BMI); obesity; prostatic neoplasm; radical prostatectomy; testosterone; visceral adiposity

\section{INTRODUCTION}

Obesity, which is a rapidly growing epidemic in the United States and worldwide, has profound implications for medical care. ${ }^{1}$ It is reported that obesity is linked to several chronic diseases and various human malignancies, including prostate cancer (PCa) ${ }^{2-4}$ As $\mathrm{PCa}$ is frequently diagnosed at a localized stage, which is suitable for radical prostatectomy (RP), in the prostate-specific antigen (PSA) era, urologists will be more frequently confronted with obese patients having localized $\mathrm{PCa}$.

The relationship between obesity and the actual pathological features of PCa has attracted more and more scholars' attention. Several studies have demonstrated that an increased body mass index (BMI) predisposes an individual to more adverse pathological characteristics. $^{5-9}$ However, other studies did not find an association between BMI and tumour grade or stage, extracapsular extension (ECE), seminal vesicle invasion (SVI), lymph node involvement (LNI) or positive surgical margins (PSMs). ${ }^{10-12}$ It is worth noting that nearly all of these studies used BMI as a marker of obesity. BMI is only an indicator of general adiposity and cannot precisely classify adiposity and lean body mass, particularly in men with more muscle mass. Additionally, BMI cannot quantify the anthropometric differences associated with fat distributions, such as visceral adipose tissue (VAT) and subcutaneous adipose tissue (SAT). These limitations of BMI may be the source of contradictory associations between obesity and PCa. In several recent studies, abdominal adiposity, and particularly the presence of a large abdominal VAT compartment, has been observed to be an important risk factor for cancer development and has been linked to adverse outcomes after curative treatments in several malignancies. ${ }^{13-16}$ Therefore, we hypothesized that abdominal fat distribution, rather than general adiposity, could provide more objective and accurate information regarding the potential influence of obesity on the clinical and pathological features of patients treated with RP. In addition, several studies have shown that in males, obesity is frequently associated with hypogonadism, which is considered to be a predictor of aggressive PCa. ${ }^{17-19}$ However, the relationship between abdominal fat distribution and the serum total testosterone level in patients with PCa remains unclear.

To evaluate the association between different anthropometric measures of obesity and clinicopathological characteristics, we conducted 
this study in 734 patients with clinically localized PCa who underwent $\mathrm{RP}$ at our institution. Furthermore, the correlation between abdominal fat distribution and the preoperative total testosterone level was investigated in the present study.

\section{MATERIALS AND METHODS}

\section{Patients and variables}

A total of 734 consecutive Chinese patients with clinically localized PCa, who received RP at Fudan University Shanghai Cancer Center from January 2006 to March 2013, were included in this study. No patient received any type of neo-adjuvant hormonal therapy before RP. All patients underwent RP at least 4 weeks after prostate biopsy. Although several of the prostate biopsies were performed at other hospitals, all biopsy specimens were centrally reviewed by two dedicated genitourinary pathologists at our institution. Histological slides of all RP specimens were assessed by the same senior genitourinary pathologist throughout the study. Magnetic resonance imaging (MRI) scans were available for review in a total of $413(56.3 \%)$ patients because certain patients had undergone MRI scans at other hospitals before surgery.

The data collected included the patients' age at surgery, height, weight, preoperative PSA level, preoperative total testosterone level, biopsy Gleason score, clinical stage, characteristics at surgery (tumour grade, tumour stage, surgical margin status and LNI), anthropometric measures of obesity (BMI, anterior abdominal fat (A), posterior abdominal fat (P), anteroposterior diameter (AP), SAT and VAT) and comorbidities (hypertension, diabetes mellitus and cardiovascular disease). The total serum testosterone level was detected in the same laboratory using Access Testosterone (Beckman Coulter, Fullerton, CA, USA), which is based on an electrochemiluminescence immunoassay technique, on the morning of prostatic surgery between 7:00 and 10:00. ${ }^{20}$ The clinical and pathological stages were determined according to the 2010 American Joint Committee on Cancer TNM classification system. Histopathological grading of the biopsy and RP specimens was performed according to the Gleason score system. A PSM was defined as the presence of cancer at the inked surface of the resected specimen. The study was approved by our institutional review board, and written informed consent was obtained from each patient before any study-specific investigation was performed.

\section{Anthropometric measures of obesity}

BMI $\left(\mathrm{kg} \mathrm{m}^{-2}\right)$ was calculated as weight in kilograms divided by height in metres squared. Anthropometric measures of abdominal adiposity, including $\mathrm{A}, \mathrm{P}$ and $\mathrm{AP}$, were measured from the T2-weighted sagittal localisation images from MRI for 413 patients (Figure 1). ${ }^{21} \mathrm{~A}$ and $\mathrm{P}$ were measured as the fat thickness between the skin and the anterior abdominal musculature or posterior musculature. All measurements were performed at the midline, which was identified at the umbilicus level, and at one cut immediately to the left and right of the midline in a blinded manner by a single person. These measurements were then averaged for the final measurement. The SAT value was calculated with the formula $\mathrm{SAT}=\mathrm{A}+\mathrm{P}$. The degree of visceral obesity was defined as the percentage of VAT (VAT\%), which was calculated according to the formula VAT\% $=[(\mathrm{AP}-\mathrm{SAT}) / \mathrm{AP}] \times 100$.

\section{Statistical analysis}

The patients' age at surgery, preoperative PSA level, preoperative total testosterone level and anthropometric measures of obesity, including BMI, SAT and the VAT\%, were treated as continuous variables. Categorical variables included BMI, the preoperative total

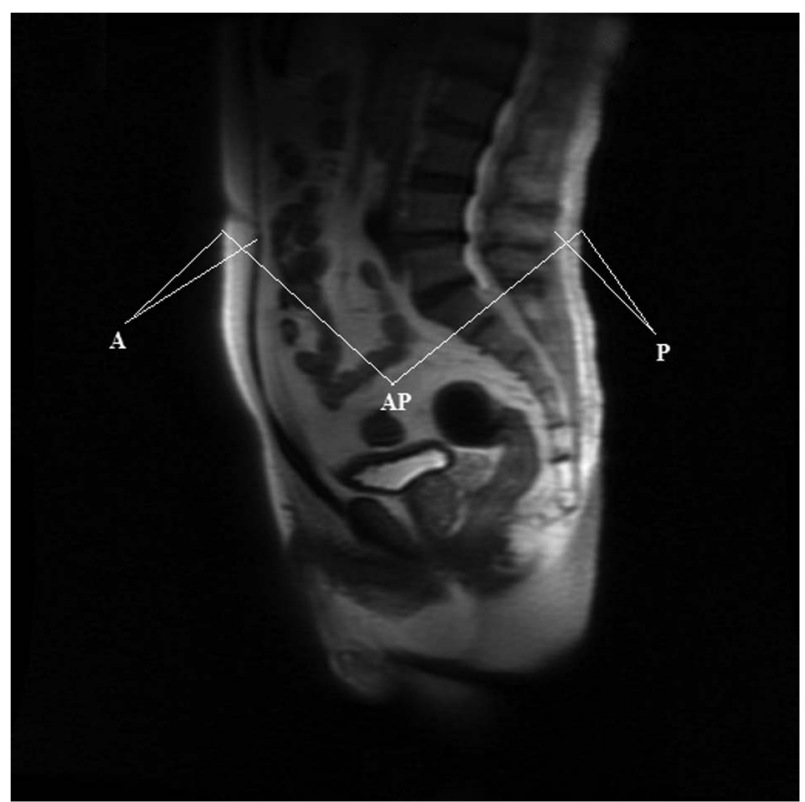

Figure 1 Representation of the T2-weighted sagittal localisation images from MRI. A, P and AP were measured in three images around the midline, and the results were averaged. $A$, anterior abdominal fat; AP, anteroposterior diameter; $\mathrm{MRI}$, magnetic resonance imaging; $P$, posterior abdominal fat.

testosterone level $\left(<250 \mathrm{ng} \mathrm{dl}^{-1} v s . \geqslant 250 \mathrm{ng} \mathrm{dl}^{-1}\right)$, clinical stage $(\mathrm{T} 1$ vs. $\geqslant \mathrm{T} 2)$, biopsy and pathological Gleason scores $(\leqslant 7$ vs. $\geqslant 8)$, the presence of ECE, SVI, a PSM, LNI and the presence of hypertension, diabetes mellitus and cardiovascular disease. Using a threshold of total testosterone $<250 \mathrm{ng} \mathrm{dl}^{-1}$ as the definition of hypogonadism, all patients were categorized into two groups: hypogonadism and eugonadism. ${ }^{19}$

We compared patient clinical and pathological characteristics across BMI groups, which were categorized according to quartiles and to the Asia-Pacific criteria of obesity $\left(<23 \mathrm{~kg} \mathrm{~m}^{-2}\right.$ : underweight or normal; 23-24.9 $\mathrm{kg} \mathrm{m}^{-2}$ : overweight; $25-29.9 \mathrm{~kg} \mathrm{~m}^{-2}$ : obese and $\geqslant 30 \mathrm{~kg} \mathrm{~m}^{-2}$ : extremely obese), ${ }^{22}$ using an analysis of variance for continuous variables and a chi-square test for categorical variables. Moreover, univariable and multivariable logistic regression models were used to address the influence of the preoperative total testosterone level and anthropometric measures of obesity on pathological outcomes. For logistic regression analyses, BMI was treated as a binary variable according to the Asia-Pacific definition of obesity $\left(<25 \mathrm{~kg} \mathrm{~m}^{-2} v\right.$ s. $\left.\geqslant 25 \mathrm{~kg} \mathrm{~m}^{-2}\right)$ because there were only $12(1.6 \%)$ patients with a BMI $\geqslant 30 \mathrm{~kg} \mathrm{~m}^{-2}$ in this study. In the multivariate models, the covariates included the patients' age at surgery, preoperative PSA level, clinical stage and biopsy Gleason score. In addition, the correlation between the total testosterone level and anthropometric measures of abdominal obesity, including the VAT\% and SAT, was quantified using Pearson's correlation coefficient. For all statistical tests, a two-sided $P<0.05$ was considered statistically significant. All statistical analyses were performed using SPSS (Statistical Package for the Social Sciences) software version 16.0 (SPSS Inc., Chicago, IL, USA).

\section{RESULTS}

The demographics and disease characteristics of the 734 patients are summarized in Table 1 . The median patient age at surgery was 68.0 years, and the median BMI was $23.8 \mathrm{~kg} \mathrm{~m}^{-2}$. The median preoperative 
Table 1 Clinicopathological characteristics of 734 patients included in this study

\begin{tabular}{|c|c|c|}
\hline Characteristics & Mean (median) & Range \\
\hline Patients, $n(\%)$ & $734(100.0)$ & \\
\hline \multicolumn{3}{|l|}{ Preoperative characteristics } \\
\hline Age at surgery (year) & $68.1(68.0)$ & $48.0-79.0$ \\
\hline $\mathrm{BMI}\left(\mathrm{kg} \mathrm{m}^{-2}\right)$ & $23.8(23.8)$ & $14.1-34.0$ \\
\hline Preoperative PSA (ng ml ${ }^{-1}$ ) & $15.8(11.0)$ & $2.4-141.9$ \\
\hline Preoperative total testosterone $\left(\mathrm{ng} \mathrm{dl}^{-1}\right)$ & $404.8(363.0)$ & $79.0-966.0$ \\
\hline \multicolumn{3}{|l|}{ Biopsy Gleason score, $n(\%)$} \\
\hline$\leqslant 6$ & $247(33.7)$ & \\
\hline 7 & $265(36.1)$ & \\
\hline$\geqslant 8$ & $222(30.2)$ & \\
\hline \multicolumn{3}{|l|}{ Clinical stage, $n(\%)$} \\
\hline $\mathrm{T} 1$ & 337 (45.9) & \\
\hline T2 & $274(37.3)$ & \\
\hline T3 & $123(16.8)$ & \\
\hline \multicolumn{3}{|l|}{ Pathological characteristics } \\
\hline \multicolumn{3}{|l|}{ Pathological Gleason score, $n(\%)$} \\
\hline$\leqslant 6$ & $141(19.2)$ & \\
\hline 7 & $354(48.2)$ & \\
\hline$\geqslant 8$ & $239(32.6)$ & \\
\hline \multicolumn{3}{|l|}{ Pathological tumour stage, $n(\%)$} \\
\hline $\mathrm{T} 2 \mathrm{a}-2 \mathrm{~b}$ & 102 (13.9) & \\
\hline T2c & $373(50.8)$ & \\
\hline ТЗа & $78(10.6)$ & \\
\hline T3b & $181(24.7)$ & \\
\hline Positive surgical margins, $n(\%)$ & $143(19.5)$ & \\
\hline Lymph node involvement, $n(\%)$ & 78 (10.6) & \\
\hline \multicolumn{3}{|l|}{ Comorbidity, $n(\%)$} \\
\hline Hypertension & $309(42.1)$ & \\
\hline Diabetes mellitus & $89(12.1)$ & \\
\hline Cardiovascular disease & $52(7.1)$ & \\
\hline \multicolumn{3}{|c|}{ Anthropometric measures of obesity on MRI $(n=413)$} \\
\hline Patients, $n(\%)$ & $413(56.3)$ & \\
\hline$A(\mathrm{~mm})$ & $16.9(16.3)$ & 5.9-36.4 \\
\hline$P(m m)$ & $14.6(14.2)$ & $4.6-34.4$ \\
\hline $\mathrm{AP}(\mathrm{mm})$ & $194.5(193.5)$ & $135.8-262.5$ \\
\hline SAT $(m m)$ & $31.5(31.4)$ & $12.6-60.3$ \\
\hline VAT $(\%)$ & $83.9(83.8)$ & $71.1-92.1$ \\
\hline
\end{tabular}

Abbreviations: A, anterior abdominal fat; AP, anteroposterior diameter; BMI, body mass index; P, posterior abdominal fat; PSA, prostate-specific antigen; SAT, subcutaneous adipose tissue; VAT, visceral adipose tissue.

PSA level and total testosterone level were $11.0 \mathrm{ng} \mathrm{ml}^{-1}$ and $363.0 \mathrm{ng} \mathrm{dl}^{-1}$, respectively. In RP specimens, a Gleason score $\geqslant 8$ was observed in $239(32.6 \%)$ patients, and the pathological tumour stage was T3 in 259 (35.3\%) patients. PSMs and LNI were observed in $143(19.5 \%)$ and $78(10.6 \%)$ patients, respectively. For 413 patients, the median SAT was $31.4 \mathrm{~mm}$, and the median VAT\% was $83.8 \%$.

When patients were classified into four groups according to the Asia-Pacific definition of obesity, no significant differences were observed in the patients' age at surgery, preoperative PSA level and total testosterone level, clinical stage, biopsy, pathological Gleason score or other pathological outcomes (all $P>0.05$, Table 2). As shown in Table 3, although binary BMI $\left(<25 \mathrm{~kg} \mathrm{~m}^{-2} v s\right.$. $\left.\geqslant 25 \mathrm{~kg} \mathrm{~m}^{-2}\right)$ was associated with a pathological Gleason score $(P=0.034)$, after adjusting for the patients' age, PSA level, clinical stage and biopsy Gleason score, BMI failed to achieve independent predictor status $(P=0.093)$. However, calculated SAT and VAT\% values were significantly associated with a pathological Gleason score, ECE and SVI (all $P<0.05$, Table 3), and such positive associations still held true for the VAT\% after multivariate adjustment (Table 3). Patients with a significantly larger VAT\% had worse pathological features. The VAT\% values were $86.9 \% \pm 2.8 \%$ and $83.1 \% \pm 1.1 \%$ in patients with pathological Gleason scores $\geqslant 8$ and $\leqslant 7$, respectively $(P<0.001)$. The VAT\% values in patients with and without ECE were $86.5 \% \pm 2.8 \%$ and $82.8 \% \pm 1.4 \%$, respectively $(P<0.001)$. The VAT\% values in patients with and without SVI were $86.8 \% \pm 2.9 \%$ and $83.1 \% \pm 1.2 \%$, respectively $(P=0.001)$.

In addition, the preoperative total testosterone level was an independent predictor of a pathological Gleason score after adjusting for patients' age, PSA level, clinical stage and biopsy Gleason score (odds ratio $(\mathrm{OR})=0.402, P=0.016$, Table 3 ). Patients with hypogonadism had a significantly higher incidence of a pathological Gleason score $\geqslant 8$ compared with patients with eugonadism. More importantly, we found that the preoperative total testosterone level was negatively correlated with the VAT\% (Pearson's correlation coefficient: $-0.485, P<0.001$, Figure 2a) and positively correlated with SAT (Pearson's correlation coefficient: $0.413, P<0.001$, Figure 2b). In patients with hypogonadism, the mean VAT\% was $86.7 \%$, which was significantly higher than in patients with eugonadism $(82.9 \%$, $P<0.001)$.

Hypertension, diabetes mellitus and cardiovascular disease were observed in $309(42.1 \%), 89(12.1 \%)$ and 52 (7.1\%) patients, respectively (Table 1). As shown in Table 2 , the incidence of hypertension, diabetes mellitus and cardiovascular disease had no significant differences when patients were stratified according to quartiles of BMI (all $P>0.05)$. However, when BMI was treated as a dichotomous variable $\left(<25 \mathrm{~kg} \mathrm{~m}^{-2} v s . \geqslant 25 \mathrm{~kg} \mathrm{~m}^{-2}\right)$, the incidence of diabetes mellitus in patients with a BMI $\geqslant 25 \mathrm{~kg} \mathrm{~m}^{-2}$ was significantly higher than in patients with a BMI $<25 \mathrm{~kg} \mathrm{~m}^{-2}$ ( $P=0.025$, data not shown). Furthermore, we found that increased visceral obesity was significantly associated with a higher incidence of hypertension and diabetes mellitus ( $P=0.022$ and $P=0.001$, respectively, data not shown).

\section{DISCUSSION}

This is the first study that investigated the association between the distribution of abdominal obesity measured on MRI and clinicopathological characteristics in Chinese patients with clinically localized PCa treated with RP. In the present study, we noted positive associations between abdominal fat distribution, and especially the VAT\%, and the risk of aggressive PCa. However, we did not find a significant correlation between BMI, an indicator of general adiposity, and any pathological feature.

In accordance with previous studies, ${ }^{10-12}$ our study demonstrated that BMI alone may not adequately capture the aggregate risk associated with obesity in relation to PCa outcomes. Modern cross-sectional imaging, such as MRI and computed tomography, may transcend the shortcomings of BMI and can be applied to assess body fat distribution. Therefore, MRI, which is routinely performed in patients with PCa for tumour staging before RP at our institution, was used to distinguish and quantify subcutaneous and visceral adipose content in this study.

Various epidemiological and experimental data have suggested the clinical significance of visceral adiposity as a risk factor for the development of PCa. In a large prospective study that included 148372 men, Pischon et al. ${ }^{23}$ reported that higher waist circumferences and waist/hip ratios (WHRs), which were surrogate measures of visceral adiposity, were positively associated with an increased risk of advanced PCa and high-grade PCa among individuals with a lower BMI. A recent study from the North Carolina-Louisiana Prostate Cancer Project, which included 1049 African-American males and 
Table 2 Comparison of clinical and pathological characteristics stratified by BMI

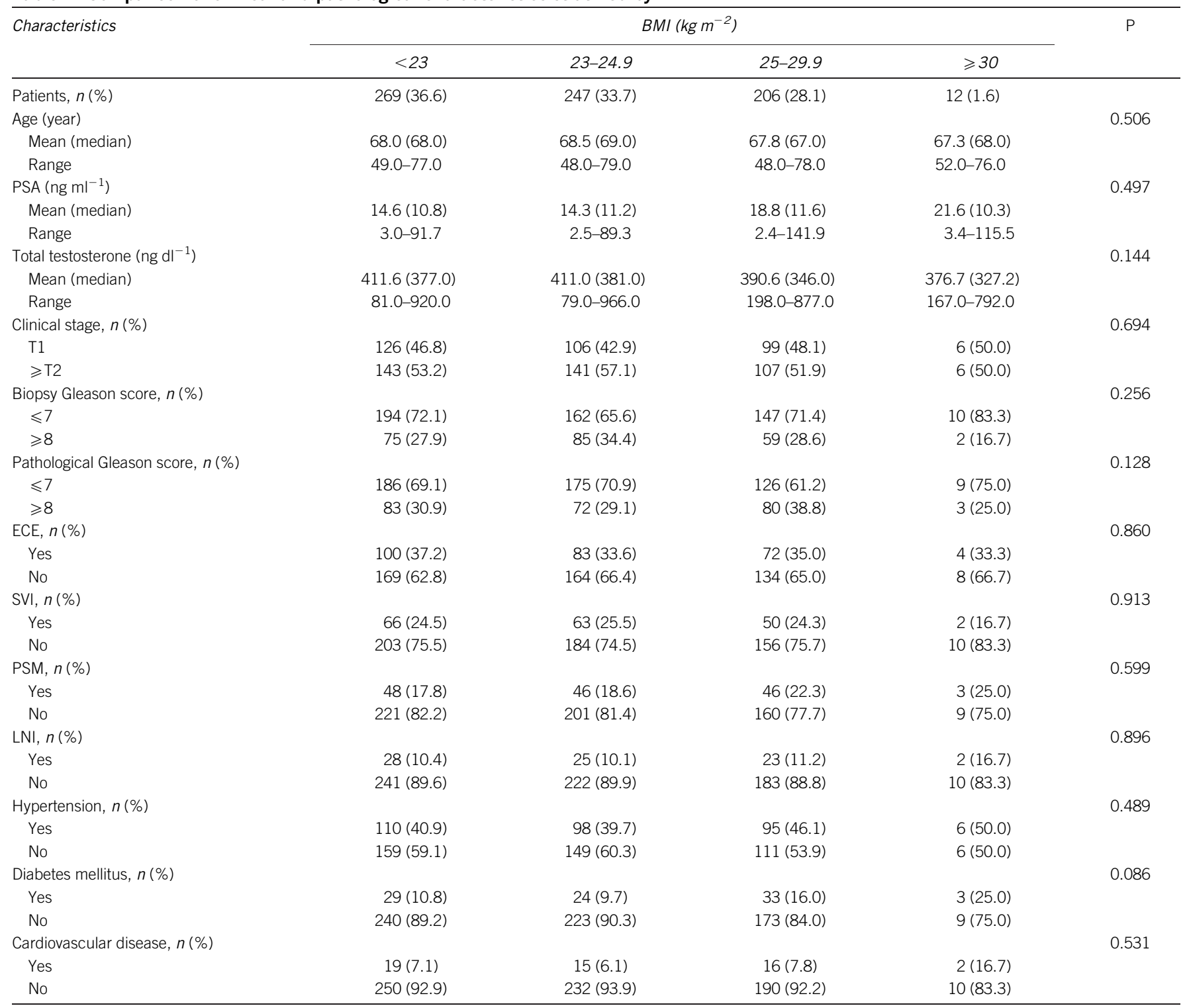

Abbreviations: BMI, body mass index; ECE, extracapsular extension; LNI, lymph node involvement; PSA, prostate-specific antigen; PSM, positive surgical margin; SVI, seminal vesicle invasion.

1083 Caucasian-American males, found that a WHR $>0.98$ among all research subjects, after adjustment for race, was significantly associated with highly aggressive PCa compared with a WHR $<0.90$ $(\mathrm{OR}=1.42) .{ }^{24}$ Similarly, our study showed that a significantly larger VAT\% was related to a worse tumour grade and a higher incidence of ECE and SVI in RP specimens. In contrast to previous studies, in our research, visceral adiposity was determined based on anthropometric measures of abdominal adipose tissue on MRI, which is more accurate than waist circumference and WHR.

Our finding that patients with more visceral fat are predisposed to having more aggressive tumours correlates with differences in metabolic activity between VAT and SAT. VAT is the most metabolically active fat and contributes to the fluctuation in levels of a large number of hormones and cytokines that play a role in the biology of PCa, including testosterone, oestrogen, sex hormone-binding globulin, insulin, insulin-like growth factor-1, interleukin-6, leptin and adiponectin. ${ }^{3,25}$ It has been reported that a lower free testosterone level in obese men may predispose these men to developing poorly differentiated, advanced disease. ${ }^{26}$ Androgens are required for the growth, maturation and differentiation of the prostate gland. It was thus suggested that testosterone may promote prostate tumour development and also help to maintain prostate tumour differentiation, which may explain why obese individuals with low testosterone levels have a higher risk of developing undifferentiated tumours. ${ }^{27}$ In the current study, we observed that patients with hypogonadism, defined as a preoperative total testosterone level $<250 \mathrm{ng} \mathrm{dl}^{-1}$, had a significantly higher incidence of a pathological Gleason score $\geqslant 8$ compared with patients with eugonadism, which was in accordance with the findings of our prior study. ${ }^{19}$ Furthermore, our present study observed that the preoperative total testosterone level was negatively correlated with the VAT\% (Pearson's correlation coefficient: $-0.485, P<0.001$ ). Based on these results, we hypothesize that a potential biological mechanism of obesity's effect on PCa is visceral adiposity that promotes the aggressiveness of a tumour by regulating serum testosterone levels. 
Table 3 Logistic regression analyses of the influence of the preoperative total testosterone level and anthropometric measures of obesity on pathological outcomes

\begin{tabular}{|c|c|c|c|c|c|}
\hline & $\begin{array}{l}\text { Pathological Gleason score } \\
\qquad(\leqslant 7 \text { vs. } \geqslant 8)\end{array}$ & $E C E$ & $S V I$ & $P S M$ & $L N I$ \\
\hline \multicolumn{6}{|l|}{ Univariable model } \\
\hline $\begin{array}{l}\left(<250 \mathrm{ng} \mathrm{dl}^{-1} \text { vs. } \geqslant 250 \mathrm{ng} \mathrm{dl}^{-1}\right),(\mathrm{OR} ; P) \\
\text { BMl }\end{array}$ & $0.324 ; 0.003$ & $0.596 ; 0.161$ & $0.798 ; 0.657$ & $0.664 ; 0.335$ & $0.397 ; 0.073$ \\
\hline$\left(<25 \mathrm{~kg} \mathrm{~m}^{-2}\right.$ vs. $\left.\geqslant 25 \mathrm{~kg} \mathrm{~m}^{-2}\right),(\mathrm{OR} ; P)$ & $1.432 ; 0.034$ & $0.974 ; 0.876$ & $0.940 ; 0.742$ & $1.302 ; 0.184$ & $1.132 ; 0.631$ \\
\hline $\mathrm{SAT},(\mathrm{OR} ; P)$ & $0.941 ; 0.003$ & $0.937 ; 0.002$ & $0.945 ; 0.009$ & $0.963 ; 0.096$ & $0.986 ; 0.609$ \\
\hline VAT\%, $(\mathrm{OR} ; P)$ & $16.818 ;<0.001$ & $8.240 ;<0.001$ & $5.881 ; 0.001$ & $3.044 ; 0.016$ & $1.473 ; 0.085$ \\
\hline \multicolumn{6}{|l|}{ Multivariable model* } \\
\hline $\begin{array}{l}\left(<250 \mathrm{ng} \mathrm{dl}^{-1} \text { vs. } \geqslant 250 \mathrm{ng} \mathrm{dl}^{-1}\right),(\mathrm{OR} ; P) \\
\quad \mathrm{BMI}\end{array}$ & $0.402 ; 0.016$ & $0.625 ; 0.259$ & $0.974 ; 0.961$ & $0.821 ; 0.666$ & $0.416 ; 0.127$ \\
\hline$\left(<25 \mathrm{~kg} \mathrm{~m}^{-2}\right.$ vs. $\left.\geqslant 25 \mathrm{~kg} \mathrm{~m}^{-2}\right),(\mathrm{OR} ; P)$ & $1.332 ; 0.093$ & $0.980 ; 0.908$ & $0.943 ; 0.765$ & $1.333 ; 0.153$ & $1.267 ; 0.378$ \\
\hline $\mathrm{SAT},(\mathrm{OR} ; P)$ & $0.962 ; 0.109$ & $0.944 ; 0.008$ & $0.939 ; 0.010$ & $0.975 ; 0.275$ & $1.001 ; 0.978$ \\
\hline VAT\%, (OR; P) & $9.618 ;<0.001$ & $6.650 ; 0.002$ & $4.419 ; 0.007$ & $1.511 ; 0.081$ & $1.245 ; 0.297$ \\
\hline
\end{tabular}

Abbreviations: BMI, body mass index; ECE, extracapsular extension; LNI, lymph node involvement; OR, odds ratio; PSA, prostate-specific antigen; PSM, positive surgical margin; SAT, subcutaneous adipose tissue; SVI, seminal vesicle invasion; VAT, visceral adipose tissue.

The preoperative total testosterone and BMI were analysed in the entire cohort (734 patients).

SAT and the VAT\% were analysed in 413 patients.

* Adjusted by age, PSA, clinical stage and biopsy Gleason score.
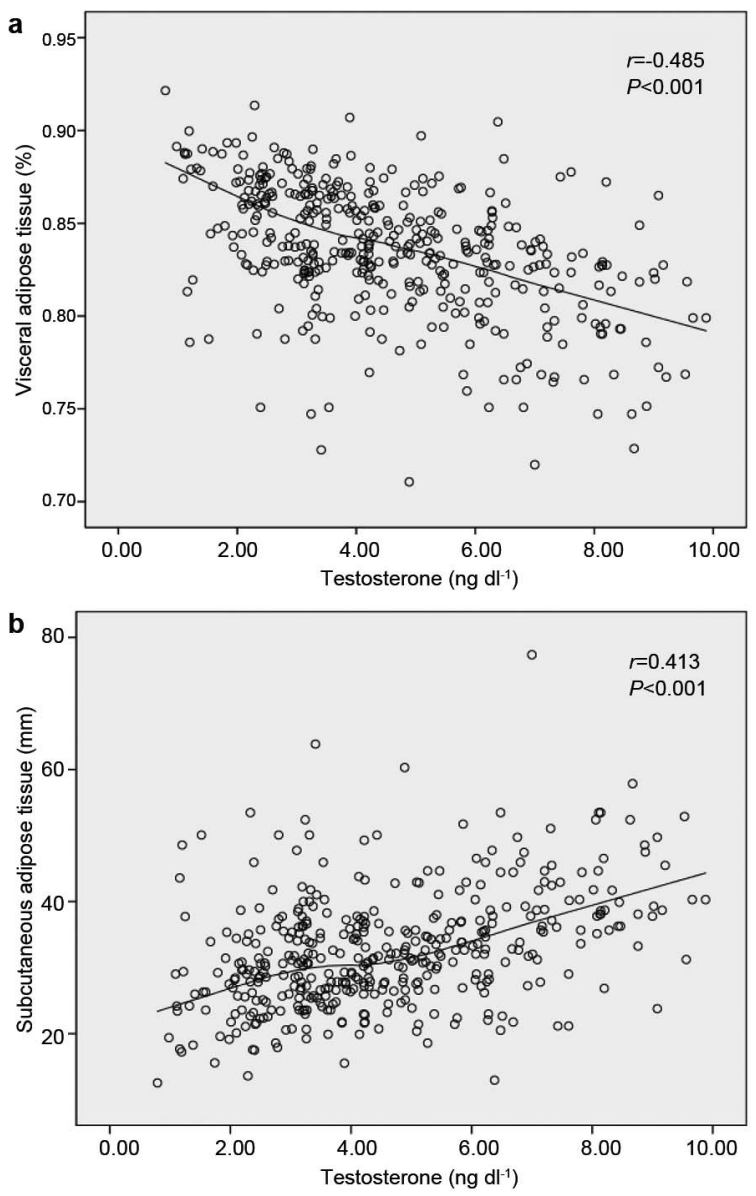

Figure 2 Scatterplots of preoperative total testosterone levels compared with the VAT\% (a) and preoperative total testosterone levels compared with SAT (b). Locally weighted scatterplot smoothing curves were fitted in plots. The preoperative total testosterone level was negatively correlated with the VAT\% $(r=-0.485$, $P<0.001)$ and positively correlated with SAT $(r=0.413, P<0.001)$. SAT, subcutaneous adipose tissue; VAT\%, percentage of visceral adipose tissue.
Obesity is associated with metabolic syndrome, which describes a cluster of comorbidities, including hypertension, elevated blood glucose, high cholesterol and abdominal obesity. Many factors in metabolic syndrome have been established as risk factors for PCa. ${ }^{28-30}$ Our data revealed that increased visceral obesity was associated with a higher incidence of hypertension and diabetes mellitus. These findings support the assumption that hypertension and diabetes mellitus resulting from an increased VAT\% may be associated with $\mathrm{PCa}$, although we did not investigate the association between these comorbidities and PCa in this study.

We acknowledge that there are certain limitations in our study. First, the VAT\% was calculated according to directly measured subcutaneous fat thickness at the umbilicus level based on MRI in this study. The indirectly calculated VAT\% may have resulted in small observed differences, as muscle, bone, spinal fluid, bowel and visceral adiposity were included within the calculation. Second, the singleinstitution nature of this study could have resulted in a potential selection bias toward our patients, although standardized surgical technique and standardized specimen evaluation at a single centre represent strengths. Despite these limitations, the results of the current study underscore the advantage of using more sophisticated anthropometric measures of abdominal adiposity than simple BMI to evaluate the risk of obesity relative to the aggressiveness of PCa.

\section{CONCLUSIONS}

In conclusion, the results of this study suggest that abdominal fat distribution, and particularly VAT\%, may be associated with a risk of advanced PCa. Moreover, the current study confirmed a significant inverse correlation between visceral adiposity and testosterone. Further studies are warranted to elucidate the biological mechanisms underlying the relationship between abdominal adiposity and the aggressiveness of $\mathrm{PCa}$.

\section{AUTHOR CONTRIBUTIONS}

YYQ and BD designed the study; collected, analysed and interpreted the clinical data; and wrote and revised the manuscript. YYK reviewed 
pathological slides and revised the manuscript. DWY supervised the project and revised the manuscript. KC, XDY, SLZ, HLZ and WYY collected part of the patients' clinical data and followed up patients. All authors vouch for the respective data and analysis, approved the final version and agreed to publish the manuscript.

\section{COMPETING FINANCIAL INTERESTS}

The authors declare that they have no financial or commercial interests related to this study.

\section{ACKNOWLEDGMENTS}

This study was supported by a grant from the International Cooperation and Exchange of Science and Technology Commission of Shanghai Municipality (No. 12410709300) and a grant from the Guide Project of Science and Technology Commission of Shanghai Municipality (No. 124119a7300).

1 Ogden CL, Carroll MD, Kit BK, Flegal KM. Prevalence of obesity in the United States, 2009-2010. NCHS Data Brief 2012; (82): 1-8.

2 Calle EE, Rodriguez C, Walker-Thurmond K, Thun MJ. Overweight, obesity, and mortality from cancer in a prospectively studied cohort of U. S. adults. $N$ Engl J Med 2003; 348: 1625-38.

3 Buschemeyer WC, Freedland SJ. Obesity and prostate cancer: epidemiology and clinical implications. Eur Urol 2007; 52: 331-43.

4 Loeb S, Yu X, Nadler RB, Roehl KA, Han M et al. Does body mass index affect preoperative prostate specific antigen velocity or pathological outcomes after radical prostatectomy? J Urol 2007; 177: 102-6.

5 Amling CL, Kane CJ, Riffenburgh RH, Ward JF, Roberts JL et al. Relationship between obesity and race in predicting adverse pathologic variables in patients undergoing radical prostatectomy. Urology 2001; 58: 723-8.

6 Boorjian SA, Crispen PL, Carlson RE, Rangel LJ, Karnes RJ et al. Impact of obesity on clinicopathologic outcomes after robot-assisted laparoscopic prostatectomy. J Endourol 2008; 22: 1471-6.

7 Castle EP, Atug F, Woods M, Thomas R, Davis R. Impact of body mass index on outcomes after robot assisted radical prostatectomy. World J Urol 2008; 26: 91-5.

8 Motamedinia P, Korets R, Spencer BA, Benson MC, McKiernan JM. Body mass index trends and role of obesity in predicting outcome after radical prostatectomy. Urology 2008; 72: 1106-10.

9 Campeggi A, Xylinas E, Ploussard G, Ouzaid I, Fabre A et al. Impact of body mass index on perioperative morbidity, oncological, and functional outcomes after extraperitoneal laparoscopic radical prostatectomy. Urology 2012; 80: 576-84.

10 Isbarn H, Jeldres C, Budäus L, Salomon G, Schlomm T et al. Effect of body mass index on histopathologic parameters: results of large European contemporary consecutive open radical prostatectomy series. Urology 2009; 73: 615-9.

11 Briganti A, Karakiewicz PI, Chun FK, Suardi N, Gallina A et al. Obesity does not increase the risk of lymph node metastases in patients with clinically localized prostate cancer undergoing radical prostatectomy and extended pelvic lymph node dissection. Int J Urol 2009; 16: 676-81.
12 Pfitzenmaier J, Pritsch M, Haferkamp A, Jakobi H, Fritsch F et al. Is the body mass index a predictor of adverse outcome in prostate cancer after radical prostatectomy in a mid-European study population? BJU Int 2009; 103: 877-82.

13 Zhu Y, Wang HK, Zhang HL, Yao XD, Zhang SL et al. Visceral obesity and risk of high grade disease in clinical T1a renal cell carcinoma. J Urol 2013; 189: 447-53.

14 Rick AS, Iannuzzi JC, Mironov O, Deeb AP, Sharma A et al. Visceral obesity and colorectal cancer: are we missing the boat with BMI? J Gastrointest Surg 2013; 17: 133-43.

15 Healy LA, Ryan AM, Carroll P, Ennis D, Crowley V et al. Metabolic syndrome, central obesity and insulin resistance are associated with adverse pathological features in postmenopausal breast cancer. Clin Oncol (R Coll Radiol) 2010; 22: 281-8.

16 von Hafe P, Pina F, Perez A, Tavares M, Barros H. Visceral fat accumulation as a risk factor for prostate cancer. Obes Res 2004; 12: 1930-5.

17 Ro hrmann S, Shiels MS, Lopez DS, Rifai N, Nelson WG et al. Body fatness and sex steroid hormone concentrations in US men: results from NHANES III. Cancer Causes Control 2011; 22: 1141-51.

18 Derby CA, Zilber S, Brambilla D, Morales KH, McKinlay JB. Body mass index, waist circumference and waist to hip ratio and change in sex steroid hormones: the Massachusetts Male Ageing Study. Clin Endocrinol (Oxf) 2006; 65: 125-31.

19 Dai B, Qu YY, Kong YY, Ye DW, Yao XD et al. Low pretreatment serum total testosterone is associated with a high incidence of Gleason score 8-10 disease in prostatectomy specimens: data from ethnic Chinese patients with localized prostate cancer. BJU Int 2012; 110: E667-72.

20 Wang C, Nieschlag E, Swerdloff R, Behre HM, Hellstrom WJ et al. Investigation, treatment, and monitoring of late-onset hypogonadism in males: ISA, ISSAM, EAU, EAA, and ASA recommendations. Eur Urol 2009; 55: 121-30.

21 Mucksavage P, Mitchell C, Kutikov A, Wein AJ, Torigian D et al. Anthropometric differences in obese men with biochemical failure after radical retropubic prostatectomy. Urol Oncol 2012; 30: 590-5.

22 World Health Organization, Western Pacific Region, International Association for the Study of Obesity. The Asia-Pacific Perspective: Redefining Obesity and Its Treatment. Sydney: Health Communications Australia Pty Limited; 2000.

23 Pischon T, Boeing $\mathrm{H}$, Weikert S, Allen N, Key T et al. Body size and risk of prostate cancer in the European prospective investigation into cancer and nutrition. Cancer Epidemiol Biomarkers Prev 2008; 17: 3252-61.

24 Su LJ, Arab L, Steck SE, Fontham ET, Schroeder JC et al. Obesity and prostate cancer aggressiveness among African and Caucasian Americans in a population-based study. Cancer Epidemiol Biomarkers Prev 2011; 20: 844-53.

25 Hoon Kim J, Lee SY, Myung SC, Kim YS, Kim TH et al. Clinical significance of the leptin and leptin receptor expressions in prostate tissues. Asian J Androl 2008; 10: 923-8.

26 Gann PH, Hennekens CH, Longcope C, Verhoek-Oftedahl W, Grodstein F et al. A prospective study of plasma-hormone levels, nonhormonal factors, and development of benign prostatic hyperplasia. Prostate 1995; 26: 40-9.

27 Freedland SJ, Platz EA. Obesity and prostate cancer: making sense out of apparently conflicting data. Epidemiol Rev 2007; 29: 88-97.

28 Håheim LL, Wisløff TF, Holme I, Nafstad P. Metabolic syndrome predicts prostate cancer in a cohort of middle-aged Norwegian men followed for 27 years. Am J Epidemiol 2006; 164: 769-74.

29 Hammarsten J, Peeker R. Urological aspects of the metabolic syndrome. Nature Reviews Urology 2011; 8: 483-94.

30 Morote J, Ropero J, Planas J, Bastarós JM, Delgado G et al. Metabolic syndrome increases the risk of aggressive prostate cancer detection. BJU Int 2013; 111: 1031-6. 